\title{
INDIVIDUALIZAÇÃO DA PENA
}

Flávio de Oliveira França, Ana Augusta Rodrigues Westin Ebaid

Universidade do Oeste Paulista - UNOESTE, Curso de Direito, Presidente Prudente, SP. E-mail: flaviofranca@gmail.com

\section{RESUMO}

No presente artigo foi apresentado um estudo histórico da individualização da pena no Brasil, iniciando com a origem da pena e a sua conceituação, breve histórico da aplicação da pena iniciando nas suas origens pré-históricas no contexto mundial, abordando as Escolas Penais e destacando a influência do Positivismo e seus desdobramentos chegando ao Pós-Positivismo. Observando em contrapartida as opções de penas não privativas de liberdade, denominadas penas alternativas e a sua aplicação aqui no Brasil. Ao final foram apresentado as falhas detectadas para a efetivação da individualização da pena e das medidas alternativas e possíveis soluções para a concretização das mesmas.

Palavras chave: Individualização da Pena, Penas Alternativas, Medidas Restritivas

\section{THE INDIVIDUALIZATION OF PUNISHMENT}

\section{ABSTRACT}

The present article presents a historical study of the individualization of punishment in Brazil starting with the origin of punishment and its definition, a brief history of the application of punishment starting with its prehistoric origins in the global context, discoursing about the Criminal Schools and contrasting the influence of the Positivism reaching to Post-Positivism. It also discourses on the other hand the options of noncustodial sentences, which is called alternative sentences and its application in Brazil. At the end, it presents the failures detected to implement the individualization of punishment and the alternative penalties and it also brings possible solutions to fulfil them.

Keywords: Individualization of Punishment, Punishment Alternatives, Measures Restrictive of Law 


\section{INTRODUÇÃO}

As notícias de presídios super lotados e presos reincidentes chamam a atenção para as formas institucionalizadas de cumprimento de sentença e sua real eficácia. Aumentar o número de presídios não parece estar funcionando em nosso país, nem o endurecimento das leis, analisados de forma isolada também não têm contribuído para a diminuição dos encarcerados.

Neste artigo vamos partir dos primórdios da aplicação da pena, com seus requintes de crueldades e sem a devida proporcionalidade, onde não existia a ressocialização dos apenados, até o ponto das penas mais humanas incentivada por organismos internacionais voltados para a análise individualizada da pena e os fatores sociais que a compõem, propondo medidas alternativas ao encarceramento como forma de ressocialização, retratando a realidade brasileira diante deste incentivo internacional e apontando possíveis soluções.

\section{METODOLOGIA}

$\mathrm{O}$ artigo foi viabilizado por pesquisas bibliográficas, leituras e fichamentos. Os dados foram analisados através do método histórico e com o referencial teórico estruturalista, culminando com análise dos fatos de forma dialética.

\section{RESULTADOS}

Os resultados obtidos através da pesquisa foram reflexivos e situacionais dentro dos problemas existentes atualmente no nosso país com propostas em conformidade com o nosso ordenamento jurídico e que podem trazer mais equilíbrio na prolação de sentenças condenatórias penais, trazendo mais efetividade ao dispositivo da individualização da pena cumulado com medidas alternativas as penas privativas de liberdade.

\section{DISCUSSÃO \\ ORIGEM DA PALAVRA PENA}

A origem da palavra pena é incerta, existindo ao menos quatro origens. Para alguns vem do termo em latim poena, significando castigo, expiação, suplício, ou ainda do latim punere (por) e pondus (peso), no sentido de pesar e restabelecer o equilíbrio dos pratos da balança da Justiça. Para outros a origem vem das palavras gregas ponos, poiné, de penomai, significando trabalho, fadiga, sofrimento e eus, de expiar, fazer o bem, corrigir, ou no sânscrito punya, com a ideia de pureza, virtude. Há quem diga que derive da palavra ultio empregada na Lei das XII Tábuas para representar o castigo como retribuição pelo mal praticado a quem desrespeitasse os mandamentos (FERREIRA, 1995).

\section{CONCEITO DE PENA}

O conceito de pena é modernamente definido como consequência jurídica arbitrada pelo Estado, que implica na diminuição de bens jurídicos ao autor da qual é imputado os fatos descritos na lei como crimes. Vários autores definem de maneira interessante, cada qual sob uma ótica, como podemos observar abaixo.

Ferreira (1995) cita que Hanz Welzel define a pena como "um mal que se impõe ao autor de um fato culpável"

Franz Von Liszt definia a pena como sendo o mal, que, por intermédio dos órgãos de administração da justiça criminal, o Estado inflige ao delinquente em razão do delito (FERREIRA, 1995).

Já para Greco (2014) a pena é “a consequência natural imposta pelo Estado quando alguém pratica uma infração penal. Quando o agente comete um fato típico, ilícito e culpável, abre-se a possibilidade para o Estado de fazer valer o seu ius puniendi." 


\section{LEVANTAMENTO HISTÓRICO DA APLICAÇÃO DAS PENAS}

Com o surgimento da vida em comunidade é observado um sistema mesmo que rudimentar de regras e punições aos infratores, para os criacionistas a pena surge ainda no paraíso quando Eva infringe uma regra, e na antiguidade estão descritas formas punitivas aos que transgredissem as lei, descritas também no código de Hamurábi e de Manu, e na Pena do Talião.

No primeiro momento surge a vingança privada, no período mais primitivo da história da pena. Esta fase prevalecia o mais forte e não guardava qualquer medida coma pessoa do criminoso ou com o crime cometido, o agente ficava sujeito ao ofendido, que defina a extensão e forma de execução da pena. A pena era geralmente mais violenta e chegava ultrapassava de longe a pessoa do infrator podendo se concentrar na sua família, ou até mesmo na sua tribo, causando dizimação desta. Esse período de total desproporção teve uma evolução com o fim de equilibrar a dosimetria da pena com a criação da Pena do Talião, e depois a composição, o "olho por olho, dente por dente", mas esta evolução também gerava absurdos. Assim como no código de Hamurábi, a retribuição na mesma medida trazia seus absurdos, a diferença aqui era com relação a alguns crimes horrendos, que poderia ser reparados pecuniariamente, com 0 infrator indenizando a vítima pelo mal causado.

Neste processo a pena ficava sujeita ao autor, o que representou um importante avanço, assim como a indenização evitava certas atrocidades.

Após essa fase inicial a humanidade entra num período negro, chamado de vingança divina, que tinha um cunho altruísta, visando purificar a alma do delinquente e aplacar a ira divina - ominis potestas a Deo (Todo Poder vem de Deus), para que a paz na Terra fosse mantida, o que levou a prática de monstruosidades em nome de Deus. Atrocidades estas que incluíam mutilação, morte por fogo ou jogados aos cães. O código de Manu (Séc. XI a.C.), sob o fundamento de que a pena purificava o infrator determinava o corte dos dedos dos ladrões.

Todas essas formas descritas anteriores evoluíram juntamente com o aumento do poder do Estado passando o mesmo a atrair para si a responsabilidade pelo direito punitivo, inicia-se a chamada vingança pública, passou a ser regulada pelo soberano e aplicada de acordo com seus interesses, não teve muita mudança, olhando do ponto de vista humanitário, não teve muita mudança, pois as penas ainda eram superiores ao delito cometido, neste período a Escola Clássica do Direito Penal começa a exercer sua influência, cominando com o lluminismo e a queda do Absolutismo.

Com o surgimento da Escola Clássica iniciou-se uma evolução histórica dentro do Direito penal trazendo profundas mudanças, trazendo como escopo o Direito Penal como ramo jurídico, não mais exercido privativamente. Outros fatos históricos corroboraram para esta nova forma de pensar, tais como: a Revolução Francesa e Declaração dos Direitos do Homem, um novo Estado liberal-democrático, com a pena como finalidade de se evitar que o criminoso repetisse a infração e não deixar que outros cidadãos infringissem a lei.

Neste período surge a ideia de legalidade e proporcionalidade na aplicação das penas, um período humanitário do Direito, tendo como postulados o crime como ente jurídico, o que significa que o crime é uma violação do direito como exigência racional; a responsabilidade penal fundada no livre arbítrio; a pena é a atribuição jurídica e restabelecimento da ordem externa violada pelo direito; método lógico-abstrato no estudo do direito penal.

O responsável pela sistematização do Direito penal e transformação em ciência penal foi Feurbach, mostrando o Direito penal como sistema liberal utilitarista, com uma função de proteger direito subjetivo. Feurbach desenvolveu os conceitos de tipicidade, trabalhou na teoria da pena com caráter de prevenção geral negativa.

Nesta sistematização surgiram duas teorias contrapostas: a Teoria da Retribuição (que era Absoluta - pena como retribuição pelo mal praticado) e a Teoria da Prevenção (que era Relativa pena com o fim utilitário e se dividia em prevenção geral e especial do crime) 
Surge neste período a transição da Escola Clássica para a Escola Positiva, que tinha como destaque que a segurança da lei penal deveria advir de um texto legal, e o surgimento da teoria das Normas de Karl BINDING e Hans KELSEN. O Direito penal com a função de proteger bens jurídicos, um Direito penal mais objetivo.

\section{PODER ESTATAL NA APLICAÇÃO DAS PENAS À PARTIR DO POSITIVISMO}

A Escola Clássica considerava a responsabilidade penal no livre arbítrio do criminoso, justificando a pena imposta ao indivíduo como merecido castigo, aplicando o mal da sanção para retribuir o mal do crime sem se preocupar com a ressocialização do criminoso, pois isso não era função do Direito Penal, em vista desta ineficácia surge um sistema de prevenção especial que traz o enfoque no estudo antropológico do homem delinquente e do crime como fato social, Cesare Lombroso e seu livro "Homem delinquente" marca o início da Escola Positiva, para ele o existia um criminoso nato, com características físicas bem definidas pela sua pesquisa em cárceres da época.

Por ter base na pessoa do criminoso, no seu perfil de maneira científica, Lombroso contribuiu de certa forma ao que nós vemos hoje em nosso sistema penal, como a individualização da pena, a personalidade do agente, conduta social (circunstâncias judiciais aplicadas pelo art. 59 do $(P)$ que são analisadas antes de ser proferida a sentença.

O Positivismo Jurídico prevalece ao jusnaturalismo com a ideia de separação entre Direito e Moral. Para o positivismo não existe relação necessária entre o Direito e a Moral, pode até haver um conteúdo moral no Direito. No entanto, o Direito é somente aquele posto pelo Estado, independente de ter conteúdo justo ou não. Neste ponto surgem as possíveis interpretações que podem ser dadas ao texto legal, mas que em alguns casos podem levar a injustiças.

Por conta dessa separação entre o Direito e a moral e as injustiças, atualmente fala-se em uma nova teoria que busca superar a dicotomia entre o Direito Natural (e seu ideal de Justiça) e o Direito Positivo (e seu ideal de segurança jurídica), o Pós-positivismo sugere uma conciliação entre Justiça e segurança jurídica, pressupondo uma reaproximação entre o Direito e a moral. Para o Pós-positivismo a norma passa a ser gênero e ter como espécies os princípios e regras de forma vinculante e obrigatória.

\section{A RELEVÂNCIA DAS PENAS ALTERNATIVAS.}

As penas alternativas surgiram como anseio de tornar as penas mais humanas e buscar a ressocialização do apenado, um dos teóricos de destaque a levantar este assunto sem dúvida foi Beccaria (1998), que era contrário as formas cruéis impostas aos infratores, que continham requintes de tortura e não de aplicação da pena, seu legado foi a proporcionalidade e o princípio da legalidade. Numa escala mundial a Declaração francesa em 1789 nos arts. 70 e 8 o trazendo a Declaração dos Direitos do Homem e do Cidadão foi documento que inspirou as Constituições dos países civilizados a prever o princípio da legalidade.

No Brasil as mudanças em direção a humanização das penas tiveram início durante o período imperial com a Constituição outorgada pelo Imperador D. Pedro I em 1824 e posteriormente pelo Código Criminal do Império em 1830 em ambos as penas sangrenta e cruéis foram abolidas e havia previsão de direitos e garantias ao brasileiros (Lyra, 1931). Mas mesmo com esses avanços o Código Criminal de 1830 ainda continha pena de morte e existia tratamento desigual em relação aos escravos.

Em 1934 houve a promulgação da Constituição da República, carta esta que extinguia as penas de morte, banimento, confisco de bens e as de caráter perpétuo com a exceção em caso de guerra declarada, isso gerou avanços e reflexos na lei penal que culminou em $1940 \mathrm{com}$ a publicação do novo Código Penal.

Já em 1946 houve nova promulgação da Constituição Federal que limitou o poder punitivo do Estado e no ano de 1948 surge a Declaração Universal de Direitos do Homem outro documento 
importante para a humanização das penas e proteção dos direitos dos apenados, Motivações essas que ensejaram em 1957 a necessidade de individualização da pena e a personalidade da pena com a edição da Lei 3274/1957 com a finalidade da sanção penal centrada na prevenção especial, ou seja, na busca da recuperação social do apenado.

Outro destaque histórico ocorreu em 1984 através da Lei 7.209/84 que trouxe para as penas criminais um papel de ressocialização, como destaque a criação do sistema progressivo de cumprimento de penas privativas de liberdade, com uma filosofia de que a sociedade não tem apenas o direito de castigar, mas que de tal castigo o indivíduo transgressor venha se ressocializar. Essa reforma deu os primeiros sinais deu os primeiros sinais de mudança na execução das penas rumo as penas alternativas.

A Constituição de 1988 também colaborou para o tratamento mais humano e digno dos presos, proteção esta expressa nos Direitos e Garantias Fundamentais, abrindo uma nova dimensão ao Direito Penal, quanto a proteção aos Bens Jurídicos emanados do novo diploma, revogação e criação de novas formas de cumprimento de penas.

Já na década de 90 a ONU criou o "Tratado de Tóquio" que vem gerando reflexos atualmente, Este conjunto de regras a serem aplicadas na administração da justiça sob a luz dos Direito Humanos, regras estas que incentivam a criação de medidas não privativas de liberdade, penas alternativas, o que gerou reflexos positivos aqui no Brasil com a edição da Lei 9099/1990 que trouxe uma forma diferenciada de punição para os crimes de menor potencial ofensivo e também posteriormente com a Lei $9.714 / 98$, leis estas que possibilitam substituição das penas privativas de liberdade, após a fixação inicial da pena para a restritiva de direitos, surgindo como formas de harmonizar e adequar o texto constitucional ao Direito Penal e Processual Penal, pois a Carta Magma em vigor no nosso país surgiu posteriormente a codificação penal e inaugurou novas formas com relação a estas normas.

\section{CONCLUSÕES}

Mesmo com a atual valorização no aspecto mundial, principalmente através da ONU para que as penas sejam mais humanas e alternativas, a realidade brasileira inspira cuidados, pois os direitos e garantias constitucionais estão postos de lado por conta de uma codificação penal que está defasada e em alguns aspectos conflitante com os mesmos. A edição de leis esparsas por si só não possuem o condão de renovar o Código Penal e o de Processo Penal, é necessário adequar estes diplomas a realidade constitucional e internacional.

Outro fator relevante para que a não efetividade da individualização da pena é a escassez de mão de obra especializada no Poder Judiciário, que pode contribuir para deixar a função do magistrado mais clara e assertiva quanto aos fatos que envolvem o apenado e as circunstâncias do delito.

Por mais sábio e desenvolto, o magistrado sozinho não tem como ter a real dimensão dos fatos sociais que envolvem a pessoa a ser julgada, e a devida individualização da pena, por isso cada vez mais se faz necessário no Processo Penal a figura do "amicus curiae", expressão latina que significa "amigo da corte" ou "amigo do tribunal", é a pessoa ou entidade estranha à causa, que vem auxiliar o tribunal, provocada ou voluntariamente, oferecendo esclarecimentos sobre questões essenciais ao processo.

Atualmente o amicus curiae não está presente nos julgados penais, ficando restrito a suprema corte e em casos bem vultosos, o que infelizmente reduz a eficácia das sentenças penais, realidade esta, alterada com a entrada em vigor do Novo Código de Processo Civil que inovou este diploma legal trazendo a possibilidade desta figura jurídica. Contudo, essa medida se torna eficaz com o emprego de mão de obra suficiente no Poder Judiciário. 


\section{REFERÊNCIAS}

BECCARIA, C. Dos Delitos e das Penas. Lisboa: Fundação Calouste Gulbenkian, 1998.

BEZERRA, R. P. da C. Origem e fundamentos das penas alternativas. Âmbito Jurídico, Rio Grande, v.17, n. 122, mar. 2014. Disponível em: <http://ambitojuridico.com.br/site/?n_link=revista_artigos_leitura\&artigo_id=14558\&revista_caderno=3>. Acesso em: 03 ago. 2016.

FERREIRA, G. Aplicação da Pena. Rio de Janeiro: Forense, 1995.

GONÇALVES, V. E. R. Penas Alternativas: Lei 9.714 de 25 de novembro de 1998. 2.ed. São Paulo: Paloma, 2003.

GRECO, R. Curso de Direito Penal. 16.ed. Rio de Janeiro: Impetus, 2014.

LIMA, L. A. P. Teoria do crime: elementos sobre a teoria neoclássica (neokantismo). Revista Jus Navigandi, Teresina, ano 20, n. 4308, 18 abr. 2015. Disponível em:

<https://jus.com.br/artigos/32411>. Acesso em: 3 ago. 2016.

LYRA, R. O centenário do código criminal. Revista dos Tribunais, São Paulo, n. 77, p.19 , 1931.

SHECAIRA, S. S.; CORRÊA JUNIOR, A. Teoria da pena: finalidades, direito positivo, jurisprudência e outros estudos de ciência criminal. São Paulo: Revista dos Tribunais, 2002.

SOUZA, C. E. F. de. Funcionalismo: a quebra da barreira entre Política Criminal e Direito Penal. IBCRIM, 24 nov. 2001. Disponível em: <http://www.ibccrim.org.br >. Acesso em: 3 ago. 2016.

SOUZA, P. S. X. de. Individualização da pena: no estado democrático de direito. Porto Alegre: Sérgio Antonio Fabris, 2006.

ZAFFARONI, E. R.; PIRANGELI, J. H. Manual de Direito Penal Brasileiro: Parte Geral. 5. ed. São Paulo: Revista dos Tribunais, 2004. 